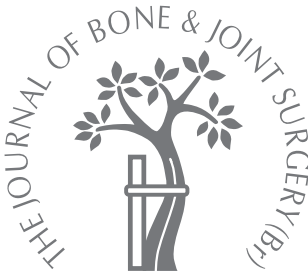

T. W. Briant-Evans, M. R. Norton, E. D. Fern

From Royal Cornwall Hospitals NHS Trust, Truro, England

\title{
Fractures of Corin 'Taper-Fit' CDH stems used in 'cement-in-cement' revision total hip replacement
}

\begin{abstract}
We describe two cases of fracture of Corin Taper-Fit stems used for cement-in-cement revision of congenital dysplasia of the hip. Both prostheses were implanted in patients in their $50 \mathrm{~s}$, with high offsets $(+7.5 \mathrm{~mm}$ and $+3.5 \mathrm{~mm})$, one with a large diameter $(48 \mathrm{~mm})$ head and one with a constrained acetabular component. Fracture of the stems took place at nine months and three years post-operatively following low-demand activity. Both fractures occurred at the most medial of the two stem introducer holes in the neck of the prosthesis, a design feature that is unique to the Taper-Fit stem. We would urge caution in the use of these particular stems for cement-in-cement revisions.
\end{abstract}

The cement-in-cement technique is an established method of revising cemented femoral components which have retained a good-quality cement mantle. By precluding the need to remove cement, this technique greatly facilitates the revision procedure. The new cemented stem is usually smaller than the one that has been removed. The short-offset neck length seen with smaller femoral implants designed for patients with congenital dysplasia of the hip $(\mathrm{CDH})$ or for the oriental market may require the use of a high-offset femoral head to restore the biomechanical axis of the hip joint. We describe the failure of Corin Taper-Fit CDH stems (Corin Group PLC, Cirencester, Gloucestershire) used for cement-in-cement revision in two cases.

\footnotetext{
T. W. Briant-Evans, MRCS Specialist Registrar in Orthopaedics

M. R. Norton, FRCS(Orth) Orthopaedic Consultant E. D. Fern, FRCS(Orth), Orthopaedic Consultant Department of Orthopaedics Royal Cornwall Hospitals NHS Trust, Treliske, Truro TR2 4HU, UK.
}

Correspondence should be sent to Mr T. W. Briant-Evans;

e-mail:

tbriantevans@hotmail.com

(C)2007 British Editorial Society of Bone and Joint Surgery doi:10.1302/0301-620X.89B3. $18200 \$ 2.00$

$J$ Bone Joint Surg $[\mathrm{Br}]$ 2007;89-B:393-5

Received 1 June 2006;

Accepted after revision

19 October 2006

\section{Case reports}

A 58-year-old woman had a revision of a right total hip replacement (THR) in March 2005. Primary bilateral THRs with cemented Exeter stems (Stryker, Howmedica Osteonics, Kalamazoo, Michigan) had been performed four years previously for osteoarthritis, but the right hip had dislocated recurrently. The acetabular component was replaced with a $56 \mathrm{~mm}$ outsidediameter, $48 \mathrm{~mm}$ inside-diameter Cormet 2000 uncemented CoCr component (Corin, Cirencester, United Kingdom). The femoral stem was revised, using the cement-in-cement technique, from an Exeter $44 \mathrm{~mm}$ offset number 1 stem to a Corin Eurocone Taper-Fit (Corin Group PLC) $\mathrm{CDH}$ size stem, with a $36 \mathrm{~mm}$ offset. This was fitted with a Corin Eurocone Cormet Modular Endo Head ('Optimom') (Corin
Group PLC), $48 \mathrm{~mm}$ in diameter (size 6) with a long $(+7.5 \mathrm{~mm}) \mathrm{CoCr}$ head offset. The largediameter head with a metal-on-metal articulation was chosen in view of the patient's young age and the history of recurrent dislocation. She made an uneventful recovery with good function, returning to work as a school teacher. Nine months later, she experienced the sudden onset of pain in the right groin on getting out of a chair. Radiographs showed a fracture through the neck of the femoral prosthesis (Figs 1 and 2). This was subsequently revised to an uncemented stem with a new, identical 48 $\mathrm{mm}$ head and when seen three months after operation, she was making good progress.

In the second case, a 51-year-old woman with a body mass index of $38.5 \mathrm{~kg} / \mathrm{m}^{2}$ had revision of a Charnley acetabular component which had been in place for 21 years with impaction grafting in 2002, and a second revision in June 2003 to improve the position of the acetabular component within the consolidated bone graft. In the second revision, the acetabular implant was replaced by a cementless Duraloc component (DePuy, Leeds, United Kingdom) and the original Charnley stem was removed to allow optimal exposure to the acetabulum. It was revised using the cement-incement technique to a Corin Eurocone Taper-Fit $\mathrm{CDH}$ stem with a $36 \mathrm{~mm}$ offset and a ceramic Corin Eurocone Modular Head, $28 \mathrm{~mm}$ in diameter with a long $(+3.5 \mathrm{~mm})$ offset. After ten days, following two dislocations, the acetabular component was again revised, this time to a Duraloc constrained liner, retaining the Taper-Fit femoral component. She made a 


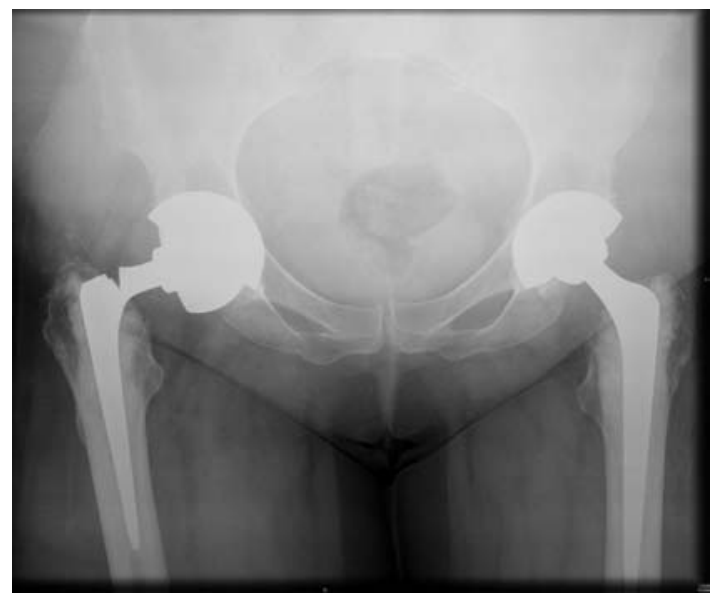

Fig. 1

Case 1 - radiograph showing the fractured Taper-Fit congenital dysplasia of the hip stem fitted with Cormet 'Optimom' Modular Endo Head, nine months after cement-incement revision.

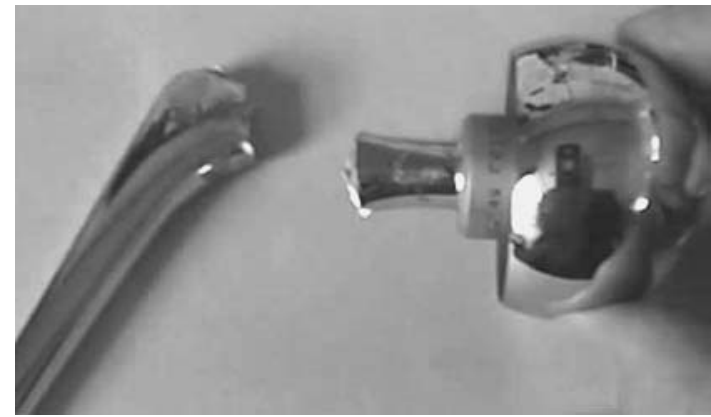

Fig. 2

Photograph showing the prosthesis from case 1, with a fracture through the stress riser at the site of the medial introducer hole in the superior part of the prosthesis neck.

good recovery from this operation and subsequently had a left THR. Almost three years later, her right hip became acutely painful and she was unable to bear weight. Radiographs showed a fracture through the neck of the femoral stem (Fig. 3). The hip was revised again using the cementin-cement technique, to an Exeter 'number 1' 37.5 mm offset stem with a neutral head (Stryker Howmedica Osteonics, Caen, France). She has made satisfactory post-operative progress at 15 months after surgery.

\section{Discussion}

The cement-in-cement technique may be used in hip surgery for revision of cemented prostheses for aseptic loosening, alterations to the version, length or offset of the stem, ${ }^{1,2}$

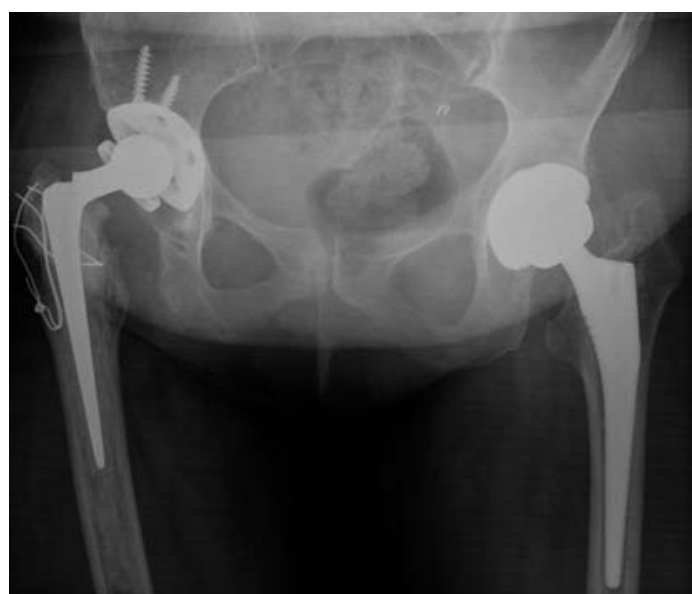

Fig. 3

Fractured stem at the head-neck junction, three years after cement-in-cement revision to a Corin Eurocone Taper-Fit congenital dysplasia of the hip stem with a ceramic Corin Eurocone Modular Head and DePuy Duraloc constrained cup.

peri-prosthetic fractures and infected prostheses. ${ }^{3}$ A recent review of 42 cases of cement-in-cement revision with a mean follow-up of 29.2 months showed no radiological evidence of loosening, and good functional results. ${ }^{4}$ It has been shown that a new chemical bond is formed between the old and new cement layers, with the shear strength being greater than that of the bone-cement interface. ${ }^{5,6}$ No failures of the femoral component have been reported to date.

Many femoral implant systems use a 'constant-offset' design which allows the head-shaft offset to be maintained even if the size of the stem is reduced to allow cement-incement revision. Implants designed primarily for use in cases of $\mathrm{CDH}$, or for the oriental market, commonly have a smaller offset. Downsizing to a CDH femoral component may then require the use of a high-offset head component in order to maintain the mechanical axis of the hip.

The Corin Taper-Fit prosthesis is a double-tapered, polished, collarless stem that emulates the design principles of Exeter-type stems. It is manufactured from stainless steel complying with ISO 5832, with a maximum carbon level of $0.08 \%$ and a nitrogen content between $0.25 \%$ and $0.5 \%$. Similarly, the stainless steel alloy used for the Exeter stem, referred to by its trade name 'Orthinox', is also a 'lowcarbon' alloy, maximum content $0.06 \%$, with identical nitrogen content. Both stems are manufactured with a highly-polished finish. The difference unique to the Corin design is at the neck-stem junction, where there is a second hole at the top of the shoulder used by the stem introducer. Mathias et $\mathrm{al}^{7}$ noted that three Taper-Fit stems subjected to five million cycles (peak load $2.3 \mathrm{kN}$ ) showed no signs of failure, and concluded that "it is possible to design a femoral component with holes in the shoulder, to accom- 
modate a stem introducer, without creating unacceptable stress concentrations". The size of stem used in the mechanical testing was not described.

The large metal-on-metal bearing used in the first case, the constrained acetabular component used in the second case, and the high offset of the heads $(+7.5 \mathrm{~mm}$ and $+3.5 \mathrm{~mm})$ contributed to higher, less predictable forces at the neck-stem junction in an implant designed for smaller patients with $\mathrm{CDH}$, and may have contributed to their failures. However, the primary pathology in both cases was $\mathrm{CDH}$, the total offset of the neck and head was not unusually high (43.5 $\mathrm{mm}$ and $39.5 \mathrm{~mm}$, respectively). Failure of the implants occurred during sedentary activity, and neither patient participated in sporting activities. The patients were not unusual in their morphology or levels of activity. The first patient had a contralateral Exeter CDH stem with $37.5 \mathrm{~mm}$ total offset that has survived for five years without failure, and remains asymptomatic. Both failures occurred within a short time of insertion, at nine months and three years, respectively. Both fractures occurred through the most medial of the two introducer holes. Analysis of the failed stems by the manufacturer (Corin) identified no manufacturing defect that would explain the failure.
The two-hole introducer system is unique to the Corin device. The manufacturer has stated that there have been no other reports of implant failure since the introduction of the Taper-Fit implant system approximately eight years ago. We urge caution in the use of these particular stems for cement-in-cement revisions. The use of small implants in these circumstances should be monitored carefully, and patients advised on the risks of fracture of the stem, particularly if they are young and active, or of large stature.

No benefits in any form have been received or will be received from a commercial party related directly or indirectly to the subject of this article.

\section{References}

1. Nelson CL. Cemented femoral revision: technique and outcome. Am J Orthop 2002;31:187-9.

2. Lieberman JR, Moeckel BH, Evans BG, Salvati EA, Ranawat CS. Cement-withincement revision hip arthroplasty. J Bone Joint Surg [Br] 1993;75-B:869-71.

3. Blake SM, Hubble MW, Howell JR, Timperley AJ, Gie GA. Results of in-cement revision of infected total hip arthroplasty. Procs British Hip Society, Edinburgh 2006.

4. Quinlan JF, O'Shea K, Doyle F, Brady OH. In cement technique for revision hip arthroplasty. J Bone Joint Surg [Br] 2006;86-B:730-3.

5. Greenwald AS, Narten NC, Wilde AH. Points in the technique of recementing in the revision of an implant arthroplasty. J Bone Joint Surg [Br] 1978;60-B:107-10.

6. Rosenstein A, MacDonald W, Iliadis A, McLardy-Smith P. Revision of cemented fixation and cement-bone interface strength. Proc Inst Mech Eng (H)1992;206:47-9.

7. Mathias KJ, Leahy JC, Heaton A, Deans WF, Hukins DW. Hip joint prosthesis design: effect of stem introducers. Med Eng Phys 1998;20:620-4. 